\title{
PAPER
}

\section{The prevalence and causes of dementia in people under the age of 65 years}

\section{R J Harvey, M Skelton-Robinson, M N Rossor}

J Neurol Neurosurg Psychiatry 2003;74:1206-1209

See end of article for authors' affiliations

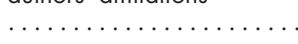

Correspondence to: Dr Harvey, Community Mental Health, The Geelong Hospital, Ryrie Street, Geelong, Victoria, Australia;

ri.harvey@virgin.net

Received

3 February 2003

In revised form

24 March 2003

Accepted 25 March 2003

\begin{abstract}
Objectives: To determine the prevalence of dementia in people under the age of 65 in a large catchment area, and use these figures to estimate the number of younger people affected by dementia in the UK.

Design: Epidemiological catchment area prevalence survey.

Setting: The London boroughs of Kensington and Chelsea, Westminster, and Hillingdon with a total population of 567500 people.

Participants: All residents of the catchment area with dementia, where the illness began before the age of 65 years. Participants were notified to the study by medical and care professionals. The diagnosis and age of onset was established from all available health and social care records. In total, 227 people were identified, of whom 185 fulfilled the inclusion criteria of having a dementia which started before their 65th birthday.

Main outcome measures: Diagnosis of dementia and differential diagnosis of the cause of the dementia.

Results: The prevalence of dementia in those aged 30-64 was 54.0 per $100000195 \% \mathrm{Cl} 45.1$ to 64.1 per 100000$)$. For those aged $45-64$ years, the prevalence was 98.1 per $100000195 \% \mathrm{Cl}$ 81.1 to 118.0 per 100000 ). From the age of 35 onwards, the prevalence of dementia approximately doubled with each 5 year increase in age. Extrapolating these figures nationally suggests that there are 18319 (15 296-21 758) people with dementia under the age of 65 in the UK.

Conclusions: The study confirms previous "guestimates" of the number of younger people affected by dementia in UK. The prevalence figures generated are robust, and are supported by other smaller and targeted prevalence surveys. The prevalence figures provided by this study will allow health planners to accurately estimate need and plan services.
\end{abstract}

n the past decade, interest and concern for younger people with dementia have dramatically increased. Following sustained campaigning and support from the Alzheimer's Society ${ }^{12}$ and other voluntary organisations ${ }^{3}$ in the UK, the needs of younger people with dementia and those who care for them have been increasingly addressed. The Royal College of Psychiatrists has recently issued guidelines recommending that every area in the country has a named old age psychiatrist responsible for younger people with dementia. ${ }^{4}$ This has been matched by the development of specialised support services, day care, and care homes for this group of patients.

However, delivering effective services relies on accurate epidemiological data to drive the planning and implementation process. In the past, estimates of the prevalence of dementia in younger people have relied on historical data ${ }^{5-8}$ drawn from hospital inpatient data and diagnostic registers. The inherent problem of studies based upon known, diagnosed cases is the potential for underestimating the real prevalence, particularly given the rarity and relatively small numbers involved. Unfortunately, because of the relatively low prevalence, conventional "door knocking" would be too costly and time consuming.

The aim of our study was to use a large, geographical catchment area and to use a combination of techniques to identify every known case of dementia starting before the age of 65 years. Having identified cases, we were also interested in exploring the prevalence of the different causes of dementia, and using the results obtained to extrapolate estimates of the numbers of younger people with dementia in the UK.

\section{METHODS}

Ethical approval was obtained from the five local research ethics committees covering the catchment areas of the London
Borough of Hillingdon ( $110 \mathrm{~km}^{2}$, population 232000 , of whom 81184 were between 30 and 64 years of age; Jarman Index $8)^{9}$ and the London boroughs of Kensington, Chelsea, and Westminster $\left(25 \mathrm{~km}^{2}\right.$, population 335500 of whom 112309 were between 30 and 64 years of age; Jarman Index 21).

\section{Sampling}

Stage 1

The aim of the first stage of sampling was to raise awareness of the project, and the need to identify and report any case, or suspected case of dementia, where the illness had started before the age of 65 years.

Personal letters and information were sent out to every general practitioner, psychiatrist, old age psychiatrist, neurologist, geriatrician, and general physician. In addition, information was also provided to departments of social services, voluntary organisations, day centres, home care, and community care teams through senior managers in the relevant organisations. The project ran in parallel with social services/ voluntary sector initiatives in both areas, ${ }^{310}$ providing senior organisational leadership across health and social services and ensuring widespread engagement with the project. Clinicians and practitioners were asked to notify any cases under their care on a defined "census" day for the study.

In parallel, hospital information systems and case registers at the four main hospitals in the catchment areas were searched for cases falling in the target age range who had relevant ICD-9/10 diagnoses.

Personal contact was made with key neurologists and psychiatrists working in the area who allowed hand searching of copies of clinic letters, discharge summaries, and departmental databases. 


\section{Stage 2}

An experienced psychiatrist (RJH) followed up notification of cases, requesting copies and/or access to all available hospital and GP case notes. The available information included clinical history, and investigations (including neuroimaging) were reviewed.

A hierarchical diagnostic algorithm was then applied. At the top level, subjects achieved a definite diagnosis if the dementia was associated with a known disease-specific genetic mutation, if there were neuropathological results available from a cerebral biopsy, or from autopsy if the patient had died after the "census" date.

At the second level of the algorithm, well recognised and validated clinical diagnostic criteria were applied to make the diagnoses of Alzheimer's disease (NINCDS/ADRDA criteria) ${ }^{11}$, vascular dementia (NINDS/AIREN criteria) ${ }^{12}$, dementia with Lewy bodies, ${ }_{13}^{13}$ frontotemporal dementia (Lund and Manchester Criteria) $)^{14}$, alcohol related dementia (DSM-IV criteria for alcohol induced persisting dementia) $)^{15}$, or other dementias for which DSM-IV criteria are available. These criteria were not applied hierarchically, but rather on the basis of best clinical opinion.

At the third level of the algorithm, patients fulfilling the DSM-IV criteria for dementia, but not fulfilling criteria for one of the above diagnostic categories were assigned to a Dementia Not Otherwise Specified category.

The age at onset of disease was defined as the age of the patient at which the earliest conclusive dementia symptom was noted or documented in the medical notes or other correspondence.

\section{Stage 3}

For half of the patients identified in stage 2, a direct approach was made through the general practitioner seeking consent for a detailed clinical assessment to confirm diagnosis. Those patients and carers willing to participate were visited at home by RJH, who completed a semi-structured interview to collect demographic details and a detailed clinical history. The clinical assessment included a medical and neurological examination and completion of the Modified Hachinski Ischaemia Scale, ${ }^{16}$ Clinical Dementia Rating Scale,${ }^{17}$ the Behavioural Pathology in Alzheimer's Disease Rating Scale, ${ }^{18}$ the Interview to Determine Deterioration in Daily Functioning, ${ }^{19}$ and the Cambridge Mental Disorders in the Elderly Examination Cognitive Assessment. ${ }^{20}$ The data collected were used to confirm the diagnosis.
Any diagnoses that were not clear at either stage 2 or stage 3 were discussed and agreed by consensus between RJH and MNR.

\section{RESULTS}

In total, 227 people with suspected young onset dementia were identified to the study. The sources of identification were psychologists $(21 \%)$, databases and case registers $(20 \%)$, neurologists (17\%), psychiatrists (14\%), social workers (9\%), GPs $(6 \%)$, physicians $(6 \%)$, community nurses $(4 \%)$, and other $(3 \%)$.

Of the 227 referrals, 19 were excluded as not fulfilling DSM-IV criteria for dementia ( six were "worried well", seven had traumatic brain injuries, two had chronic schizophrenia, and four cases identified from hospital information systems were clearly miscoded when the notes were reviewed).

Of the remaining 208 cases, review of the notes showed an age of onset greater than 65 years of age in 23 cases who were further excluded from the study. The remaining 185 cases formed the population for the prevalence study, and of these, 87 cases $(47 \%)$ underwent a detailed stage 3 personal assessment.

In the stage 3 assessment group, 69 patients (83\%) had undergone neuroimaging with either CT or MRI, with 18 (21\%) having undergone both CT and MRI. Twenty one patients $(24 \%)$ had had an EEG.

The mean age of the population was 58.7 years (95\% CI 57.4 to 60.1 years). Fifty eight percent (95\% CI 50.9 to $65.6 \%$ ) were male and $42 \%$ (95\% CI 34.4 to $49.1 \%$ ) were female, suggesting a trend towards a higher prevalence of dementia in males than females.

Table 1 summarises the age and gender specific prevalence rates for dementia in the study population on the "census" day; the pattern of prevalence approximately doubles with each five year increase in age.

Pragmatically, mixed diagnoses were avoided and we aimed to make a "highest confidence" single diagnosis in each case. In $168(90 \%)$ of cases a single diagnosis was established using the diagnostic algorithm, 19 cases ( $10 \%)$ fitted more than one set of criteria and required a clinical consensus diagnosis to be made. Differential diagnoses in the population included Alzheimer's disease (62 cases, 34\%), vascular dementia (34 cases, $18 \%$ ), frontotemporal dementia ( 23 cases, $12 \%$ ), alcohol related dementia (19 cases, 10\%), and dementia with Lewy bodies ( 12 cases, $7 \%$ ). Other causes of dementia accounted for 35 cases $(19 \%)$ and included Huntington's disease (nine

Table 1 Age and gender specific prevalence rates in the study population

\begin{tabular}{|c|c|c|c|c|c|c|c|c|c|c|c|c|}
\hline \multirow{2}{*}{\multicolumn{3}{|c|}{ Population }} & \multicolumn{9}{|c|}{ All causes of dementia } & \multirow[b]{3}{*}{ Significance $†$} \\
\hline & & & \multicolumn{3}{|l|}{ All } & \multicolumn{3}{|c|}{ Male } & \multicolumn{3}{|c|}{ Female } & \\
\hline Age range & Male (n) & Female (n) & $\mathrm{n}$ & Rate* & $95 \% \mathrm{Cl}$ & $\mathrm{n}$ & Rate & $95 \% \mathrm{Cl}$ & $\mathrm{n}$ & Rate & $95 \% \mathrm{Cl}$ & \\
\hline $30-34$ & 23898 & 23375 & 6 & 12.7 & $(4.7$ to 26.7$) \ddagger$ & 3 & 12.6 & (2.6 to 36.7$)$ & 3 & 12.8 & (2.7 to 37.5$)$ & NS \\
\hline $35-39$ & 18526 & 19106 & 3 & 8.0 & (1.6 to 23.3$)$ & 1 & 5.4 & $(0.1$ to 30.1$)$ & 2 & 10.5 & $(1.3$ to 37.8$)$ & NS \\
\hline $40-44$ & 18982 & 19643 & 6 & 15.5 & (5.7 to 33.8 ) & 1 & 5.3 & (0.1 to 29.4 ) & 5 & 25.5 & (8.3 to 59.4 ) & NS \\
\hline $45-49$ & 16549 & 16799 & 11 & 33.0 & (16.5 to 59.0 ) & 6 & 36.3 & (13.3 to 78.9$)$ & 5 & 29.8 & $(9.7$ to 69.5$)$ & NS \\
\hline $50-54$ & 15185 & 15237 & 19 & 62.5 & (37.6 to 97.5$)$ & 10 & 65.9 & (31.6 to 121$)$ & 9 & 59.1 & (27 to 112 ) & NS \\
\hline $55-59$ & 13983 & 13626 & 42 & 152.1 & (1 10 to 206 ) & 28 & 200.2 & (133 to 289 ) & 14 & 102.7 & (56.2 to 172 ) & NS \\
\hline $60-64$ & 12716 & 13141 & 43 & 166.3 & (120 to 224 ) & 26 & 204.5 & (134 to 300 ) & 17 & 129.4 & (75.4 to 207 ) & NS \\
\hline $30-64$ & 119839 & 120927 & 130 & 54.0 & (45.1 to 64.1$)$ & 75 & 62.6 & (49.2 to 78.4$)$ & 55 & 45.5 & (34.3 to 59.2 ) & NS \\
\hline $45-64$ & 58433 & 58803 & 115 & 98.1 & (81.1 to 118 ) & 70 & 119.8 & (93.4 to 151.0 ) & 45 & 76.5 & (55.8 to 102 ) & NS \\
\hline Over $65 \S$ & & & 55 & & & 33 & & & 22 & & & \\
\hline
\end{tabular}

*Rate per 100000 people at risk.

tSignificance of difference between genders by inference from $95 \% \mathrm{Cl}$.

$\$ 95 \%$ confidence interval for the prevalence rate.

$\S$ Subjects who had a dementia starting before the age of 65 years, but were over 65 but still living on the study census day. 
Table 2 Age specific prevalence rates for the most common causes of young onset dementia

\begin{tabular}{|c|c|c|c|c|c|c|c|c|c|c|c|c|}
\hline \multirow[b]{2}{*}{ Age range } & \multicolumn{3}{|c|}{ Alzheimer's disease } & \multicolumn{3}{|c|}{ Vascular dementia } & \multicolumn{3}{|c|}{ Frontotemporal dementia } & \multicolumn{3}{|c|}{ Alcohol related dementia } \\
\hline & $\mathrm{n}$ & Rate* & $95 \% \mathrm{Cl}$ & $\mathrm{n}$ & Rate* & $95 \% \mathrm{Cl}$ & $\mathrm{n}$ & Rate* & $95 \% \mathrm{Cl}$ & $\mathrm{n}$ & Rate & $95 \% \mathrm{Cl}$ \\
\hline $40-44$ & 1 & 2.6 & (0.7 to 14.4$)$ & & & & & & & & & \\
\hline $45-49$ & 2 & 6.0 & (0.7 to 21.7$)$ & & & & 4 & 12.0 & (3.3 to 30.7$)$ & 2 & 6.0 & (0.7 to 21.7$)$ \\
\hline $50-54$ & 5 & 16.4 & $(5.3$ to 38.4$)$ & 2 & 6.6 & (0.8 to 24.4$)$ & 1 & 3.3 & $(0.8$ to 18.3$)$ & 6 & 19.7 & $(7.2$ to 42.9$)$ \\
\hline $55-59$ & 14 & 50.7 & (27.7 to 85.1$)$ & 9 & 32.6 & (14.9 to 67.9 ) & 7 & 25.4 & (10.2 to 52.2 ) & 5 & 18.1 & (5.9 to 42.3 ) \\
\hline $60-64$ & 20 & 77.3 & (47.2 to 119 ) & 10 & 38.7 & (18.5 to 71.1$)$ & 6 & 23.2 & $(8.5$ to 50.5$)$ & 3 & 11.6 & (2.4 to 33.9 ) \\
\hline $30-64$ & 42 & 17.4 & $(12.6$ to 23.6$)$ & 21 & 8.7 & (5.4 to 13.3$)$ & 18 & 7.5 & (4.4 to 11.8 ) & 16 & 6.6 & (3.8 to 10.8 ) \\
\hline $45-64$ & 41 & 35.0 & (25.1 to 47.4 ) & 21 & 17.9 & (11.1 to 27.4 ) & 18 & 15.4 & $(9.1$ to 24.3$)$ & 16 & 13.6 & (7.8 to 22.2$)$ \\
\hline
\end{tabular}

Table 3 Estimated numbers of cases of dementia in people under the age of 65 in the UK

\begin{tabular}{|c|c|c|c|c|c|c|}
\hline Age & $\begin{array}{l}\text { UK Population } \\
2001\end{array}$ & All causes of dementia & Alzheimer's disease & Vascular dementia & $\begin{array}{l}\text { Frontotemporal } \\
\text { dementia }\end{array}$ & $\begin{array}{l}\text { Alcohol related } \\
\text { dementia }\end{array}$ \\
\hline $30-34$ & 4493585 & 570 (209 to 1240$)^{*}$ & & & & \\
\hline $35-39$ & 4625810 & 369 (76 to 1078$)$ & & & & \\
\hline $40-44$ & 4151580 & 645 (237 to 1403 ) & 107 (27 to 598$)$ & & & \\
\hline $45-49$ & 3735964 & 1232 (616 to 2204 ) & $224(27$ to 811$)$ & & 448 (122 to 1147$)$ & 224 (27 to 811$)$ \\
\hline $50-54$ & 4040437 & 2523 (1519 to 3939 ) & 664 (216 to 1552 ) & 266 (32 to 96 ) & 133 (34 to 739$)$ & 797 (293 to 1733) \\
\hline $55-59$ & 3338861 & 5079 (3673 to 6878$)$ & $1693(925$ to 2841$)$ & 1088 (497 to 2267$)$ & 847 (341 to 1743 ) & 605 (196 to 1412$)$ \\
\hline $60-64$ & 2879948 & 4789 (3456 to 6451$)$ & 2228 (1359 to 3427$)$ & 1114 (533 to 2048$)$ & $668(245$ to 1454$)$ & 334 (69 to 976$)$ \\
\hline $30-64$ & 27266185 & 18319 (15296 to 21758$)$ & 5918 (4254 to 7989 ) & 2959 (1832 to 4526$)$ & 2536 (1502 to 4008$)$ & 2255 (1290 to 3654$)$ \\
\hline $45-64$ & 13995210 & 13728 (1134 to 16514$)$ & 4894 (3513 to 6634$)$ & 2507 (1553 to 3835$)$ & 2149 (1274 to 3401$)$ & 1910 (1092 to 3107) \\
\hline
\end{tabular}

* $95 \%$ confidence interval of the estimate.

cases), dementia in multiple sclerosis (eight cases), corticobasal degeneration (two cases), prion disease (two cases), dementia in Down's syndrome (three cases), dementia in Parkinson's disease (two cases), and dementia not otherwise specified (nine cases). The very low prevalence of dementia in Down's syndrome is likely to be an artefact due to sampling bias. Despite raising awareness of the project with learning disability services, no referrals of cases were made from these sources.

The age specific prevalence rates for the four most common causes of dementia in this group of younger people are summarised in table 2 .

\section{Estimates of numbers of cases in the UK}

One of the objectives of the study was to generate robust estimates of the numbers of people in the UK with young onset dementia. These figures are important both for service planning and for campaigning for improvements in recognition and provision.

Using data from the 2001 UK Census, we applied the prevalence figures derived from our population to the population figures for the UK. Table 3 summarises the estimated numbers of younger people with dementia, and with specific diagnoses in the UK.

\section{DISCUSSION}

This is the first study to report the prevalence of dementia and differential diagnoses in a community based catchment area study of younger people with dementia. The prevalence of dementia in people between the ages of 30 and 64 years was 54 per 100000 with the prevalence approximately doubling for each five year age band. Based on the prevalence figures derived from this study we estimate that there are 18319 (15 296-21 758) people under the age of 65 years with dementia in the UK.

The main strength of the study is the combination of a large catchment area and the use of multiple and varied means of case identification, essentially attempting to leave no stone unturned. The very varied sources of case identification confirm the benefits of this methodology. The main weakness of the study is that despite using a catchment area with a population of more than 500000 people, the rarity of the condition meant that only 185 cases were identified. For more robust estimates with smaller confidence intervals a much larger population would be helpful.

This study was unique in being large enough to consider a range of differential diagnoses with our disease specific figures and overall figures being supported by other studies of individual diseases.

Thus our prevalence figure for young onset Alzheimer's disease of 35.0 per 100000 in the 45-64 years age group is very similar to estimates for the Northern Region (34.6), ${ }^{6}$ Finland $(32.7),{ }^{21}$ the Framingham Study (31.8), ${ }^{22}$ and Cambridge (15.1). ${ }^{8}$

Similarly, the prevalence rates we found for vascular dementia were close to the estimates derived from an earlier study in Scotland, ${ }^{5}$ and the prevalence rate we identified for frontotemporal dementia ( 15.4 per 100000 ) was almost identical to the rate identified in the Cambridge study (15.1). ${ }^{8}$

While none of these studies used an identical methodology, this study is probably most similar to the study from the Northern Region which used case ascertainment from hospital inpatient records, and the Cambridge study which identified cases from memory clinic databases and admission records. The Framingham study and the Finnish study both used ascertainment from large population diagnostic registers, but generate similar prevalence figures. One conclusion from this is that younger people with dementia inevitably come to medical attention and receive a diagnosis-what is less certain is what follow up and support these patients are given after the diagnosis.

Our study underpins and supports initiatives from the Alzheimer's Society and the Royal College of Psychiatrists to secure and improve services for this group of patients. Even though dementia in younger people is uncommon when compared with dementia in older people, every case is a personal 
tragedy for the individual and their family, which often includes young children.

The study also highlights the differences between dementia in younger people and dementia in older people. Alzheimer's disease is considerably less common in this group, accounting for only $34 \%$ of cases, whereas in the elderly it would be expected to account for up to $80 \%$ of cases. Moreover, unusual diseases such as frontotemporal dementia accounts for $12 \%$ of cases, although there is increasing evidence that it is a commonly missed diagnosis in older people. ${ }^{23}$

The prevalence data generated by this study can be applied to local population figures to derive reliable estimates of the potential numbers of cases in any area. This should support better planning and delivery of services.

\section{ACKNOWLEDGEMENTS}

Project funded by NHS Executive (North Thames) Responsive R\&D Grant, RFG045. Richard Harvey is funded by the Alzheimer's Society.

Funding was awarded in open competition and following peer review. The funder had no role in study design, data collection, analysis, interpretation of data, or in the writing of the report. The funder encouraged us to submit the paper for publication as part of good research governance.

Competing interests: none declared

\section{Authors' affiliations}

R J Harvey, M N Rossor, Imperial College London and the Institute of Neurology (UCL), London, UK

M Skelton-Robinson, Woodlands Centre, Hillingdon Hospital, Hillingdon, UK

\section{REFERENCES}

1 Alzheimer's Disease Society. Younger People with Dementia: a review and strategy. London: Alzheimer's Disease Society, 1996.

2 Alzheimer's Society. Younger people with dementia: a guide to service development and provision. London: Alzheimer's Society, 2001.

3 Quinn, C. The Care Must Be There. London: Dementia Relief Trust, 1996.

4 Royal College of Psychiatrists. Services for Younger People with Alzheimer's Disease and other Dementias. CR77. London: Royal College of Psychiatrists, 2000.
5 McGonigal G, Thomas B, McQuade C, et al. Epidemiology of Alzheimer's presenile dementia in Scotland, 1974-88. BM 1993;306:680-3.

6 Newens AJ, Forster DP, Kay DW, et al. Clinically diagnosed presenile dementia of the Alzheimer type in the Northern Health Region: ascertainment, prevalence, incidence and survival. Psychol Med 1993:23:631-44.

7 Woodburn K, Johnstone E. Ascertainment of a population of people with early-onset dementia in Lothian, Scotland. Int J Geriatr Psychiatry 1999; 14:362-7.

8 Ratnavalli E, Brayne C, Dawson K, et al. The prevalence of frontotemporal dementia. Neurol 2002;58:1615-21.

9 Jarman B. Identification of underprivileged areas. BM 1983;286:1705-9.

10 Kirk L, Smith M, Templeton H, et al. Early Onset Dementia (Pre-senile Dementia): A Case of Need. Hillingdon: Health and Social Service Purchasing Agencies, 1995.

11 McKhann G, Drachman D, Folstein M, et al. Clinical diagnosis of Alzheimer's Disease: Report of the NINCDS-ADRDA work group under the auspices of Department of Health and Human Services Task Force on Alzheimer's Disease. Neurol 1984;34:939-44.

12 Roman GC, Tatemichi TK, Erkinjuntti T, et al. Vascular Dementia: Diagnostic criteria for research studies. Report of the NINDS-AIREN International Workshop. Neurol 1993;43:250-60.

13 McKeith IG, Galasko D, Kosaka K, et al. Consensus guidelines for the clinical and pathologic diagnosis of dementia with Lewy bodies (DLB): Report of the consortium on DLB international workshop. Neurol 1996; 47: $1113-24$.

14 The Lund and Manchester Groups. Clinical and neuropathological criteria for frontotemporal dementia. J Neurol Neurosurg Psychiatry 1994:57:416-8.

15 American Psychiatric Association. Diagnostic and Statistical Manual of Mental Disorders, 4th edn (DSM-IV). Washington DC: APA, 1994.

16 Rosen WG, Terry RD, Fuld PA, et al. Pathological verification of ischemic score in differentiation of dementias. Ann Neurol 1980;7:486-8.

17 Hughes CP, Berg L, Danziger WL, et al. A new clinical scale for the staging of dementia. Brit J Psychiatry 1982;140:566-72.

18 Reisberg B, Borenstein J, Salob SP, et al. Behavioral symptoms in Alzheimer's disease: phenomenology and treatment. J Clin Psychiatry 1987;48 Suppl:9-15.

19 Teunisse S, Mayke M, Van Creval H. Assessing the severity of dementia. Arch Neurol 1991:48:274-7.

20 Blessed G, Black SE, Butler T, et al. The diagnosis of dementia in the elderly. A comparison of CAMCOG (the Cognitive section of CAMDEX), the AGECAT program, DSM-III, the Mini-Mental State Examination and some short rating scales. Brit J'Psychiatry 1991;159:193-8.

21 Sulkava R, Wikstrom J, Aromaa A, et al. Prevalence of severe dementia in Finland. Neurol 1985;35:1025-9.

22 Kokmen E, Beard CM, Offord KP, et al. Prevalence of medically diagnosed dementia in a defined United States population: Rochester, Minnesota, January 1 1975. Neurol 1989;39:773-6.

23 Stevens $T$, Livingston $G$, Kitchen $G$, et al. Islington study of dementia subtypes in the community. Brit J Psychiatry 2002;180:270-6. 